\title{
Absence of Apparent Transmission of SARS-CoV-2 from Two Stylists After Exposure at a Hair Salon with a Universal Face Covering Policy - Springfield, Missouri, May 2020
}

\author{
M. Joshua Hendrix, MD ${ }^{1}$; Charles Walde, $\mathrm{MD}^{2}$; Kendra Findley, $\mathrm{MS}^{3}$; Robin Trotman, DO ${ }^{4}$
}

\begin{abstract}
On July 14, 2020, this report was posted as an MMWR Early Release on the MMWR website (https://www.cdc.gov/mmwr).
\end{abstract}

On May 12, 2020 (day 0), a hair stylist at salon A in Springfield, Missouri (stylist A), developed respiratory symptoms and continued working with clients until day 8 , when the stylist received a positive test result for SARS-CoV-2, the virus that causes coronavirus disease 2019 (COVID-19). A second hair stylist (stylist B), who had been exposed to stylist A, developed respiratory symptoms on May 15, 2020 (day 3), and worked with clients at salon A until day 8 before seeking testing for SARS-CoV-2, which returned a positive result on day 10 . A total of 139 clients were directly serviced by stylists A and B from the time they developed symptoms until they took leave from work. Stylists A and B and the 139 clients followed the City of Springfield ordinance* and salon A policy recommending the use of face coverings (i.e., surgical masks, N95 respirators, ${ }^{\dagger}$ or cloth face coverings) for both stylists and clients during their interactions. Other stylists at salon A who worked closely with stylists A and B were identified, quarantined, and monitored daily for 14 days after their last exposure to stylists A or B. None of these stylists reported COVID-19 symptoms. After stylist B received a positive test result on day 10, salon A closed for 3 days to disinfect frequently touched and contaminated areas. After public health contact tracings and 2 weeks of follow-up, no COVID-19 symptoms were identified among the 139 exposed clients or their secondary contacts. The citywide ordinance and company policy might have played a role in preventing spread of SARS-CoV-2 during these exposures. These findings support the role of source control in preventing transmission and can inform the development of public health policy during the COVID-19 pandemic. As stay-at-home orders are lifted, professional and social interactions in the community will present more opportunities for spread of SARS-CoV-2. Broader implementation of masking policies could mitigate the spread of infection in the general population.

Stylist A worked from day 0 to day 8 with COVID-19 symptoms before receiving a diagnosis of COVID-19 by polymerase chain reaction (PCR) testing. Although self-isolation

\footnotetext{
* Springfield, Missouri, city ordinance went into effect May 6, 2020, restricted seating in waiting areas to $25 \%$ of normal capacity and recommended social distancing and use of face coverings for employees and clients when social distancing was not or could not be followed. https://www.springfieldmo. gov/5140/Masks-and-Face-Coverings.

$\dagger$ Particulate-filtering facepiece respirators that filter $\geq 95 \%$ of airborne particles (https://www.cdc.gov/niosh/npptl/topics/respirators/disp_part/n95list1.html).
}

was recommended after testing on day 6, stylist A continued to work until the test returned a positive result, at which time stylist A was excluded from work by salon A. On day 3, after working with stylist A, stylist B developed respiratory symptoms. During Stylist A's symptomatic period, the two stylists interacted while neither was masked during intervals between clients. Stylist B worked from day 3 to day 8 while symptomatic before self-isolating and seeking PCR testing, which returned a positive result for SARS-CoV-2 on day 10. Stylist A worked with clients for 8 days while symptomatic, as did stylist B for 5 days. During all interactions with clients at salon A, stylist A wore a double-layered cotton face covering, and stylist B wore a double-layered cotton face covering or a surgical mask.

The Greene County Health Department (Missouri) conducted contact tracing for all 139 exposed clients back to the dates that stylists A and B first developed symptoms. The 139 clients were monitored after their last exposure at salon A. Clients were asked to self-quarantine for 14 days and were called or sent daily text messages to inquire about any symptoms; none reported signs or symptoms of COVID-19. Testing was offered to all clients 5 days after exposure, or as soon as possible for those exposed $>5$ days before contact tracing began. Overall, $67(48.2 \%)$ clients volunteered to be tested, and 72 (51.8\%) refused; all 67 nasopharyngeal swab specimens tested negative for SARS-CoV-2 by PCR. Telephone interviews were attempted 1 month after initial contact tracings to collect supplementary information. Among the 139 exposed clients, the Greene County Health Department interviewed 104 (74.8\%) persons.

Among the 139 clients, the mean age was 52 years (range $=21-93$ years); 79 clients $(56.8 \%)$ were male (Table 1$)$. Salon appointments ranged from 15 to 45 minutes in length (median $=15$ minutes; mean $=19.5$ minutes $)$. Among the 104 interviewed clients, $102(98.1 \%)$ reported wearing face coverings for their entire appointment, and two (1.9\%) reported wearing face coverings part of the time (Table 2). Types of face covering used by clients varied; $49(47.1 \%)$ wore cloth face coverings, $48(46.1 \%)$ wore surgical masks, five $(4.8 \%)$ wore N95 respirators, and two (1.9\%) did not know what kind of face covering they wore. Overall, $101(97.1 \%)$ interviewed clients reported that their stylist wore a face covering for the entire appointment; three did not know. When asked about the type of face coverings worn by the stylists, $64(61.5 \%)$ reported that their stylist wore a cloth face covering $(39 ; 37.5 \%)$ or surgical mask 


\section{Summary}

What is already known about this topic?

Consistent and correct use of cloth face coverings

is recommended to reduce the spread of SARS-CoV-2.

What is added by this report?

Among 139 clients exposed to two symptomatic hair stylists with confirmed COVID-19 while both the stylists and the clients wore face masks, no symptomatic secondary cases were reported; among 67 clients tested for SARS-CoV-2, all test results were negative. Adherence to the community's and company's face-covering policy likely mitigated spread of SARS-CoV-2.

What are the implications for public health practice?

As stay-at-home orders are lifted, professional and social interactions in the community will present more opportunities for spread of SARS-CoV-2. Broader implementation of face covering policies could mitigate the spread of infection in the general population.

(25; 24.0\%); 40 (38.5\%) clients did not know or remember the type of face covering worn by stylists. When asked whether they had experienced respiratory symptoms in the 90 days preceding their appointment, $87(83.7 \%)$ clients reported that they had not. Of those who did report previous symptoms, none reported testing for or diagnosis of COVID-19.

Six close contacts of stylists A and B outside of salon A were identified: four of stylist A and two of stylist B. All four of stylist A's contacts later developed symptoms and had positive PCR test results for SARS-CoV-2. These contacts were stylist A's cohabitating husband and her daughter, son-in-law, and their roommate, all of whom lived together in another household. None of stylist B's contacts became symptomatic.

\section{Discussion}

SARS-CoV-2 is spread mainly between persons in close proximity to one another (i.e., within 6 feet), and the more closely a person interacts with an infected person and the longer the interaction, the higher the risk for transmission (1). At salon A in Springfield, Missouri, two stylists with COVID-19 symptoms worked closely with 139 clients before receiving diagnoses of COVID-19, and none of their clients developed COVID-19 symptoms. Both stylists A and B, and $98 \%$ of the interviewed clients followed posted company policy and the Springfield city ordinance requiring face coverings by employees and clients in businesses providing personal care services. The citywide ordinance reduced maximum building waiting area seating to $25 \%$ of normal capacity and recommended the use of face coverings at indoor and outdoor public places where physical distancing was not possible. Both company and city policies were likely important factors in preventing the spread of SARS-CoV-2 during these interactions
TABLE 1. Characteristics* of clients $(N=139)$ who visited hair salon $A$ and were exposed to stylists A and B with COVID-19 - Springfield, Missouri, May 2020

\begin{tabular}{lc}
\hline Characteristic & Value \\
\hline Demographic characteristic & $79(56.8)$ \\
Male, no. (\%) & $52(21-93)$ \\
Age, yrs. mean (range) & \\
Encounter information & May $12-20\left(\right.$ days $\left.0-8^{\dagger}\right)$ \\
Appointment date range & $84(60.4)$ \\
Exposure to stylist A, no. (\%) & $55(39.6)$ \\
Exposure to stylist B, no. (\%) & $15(15-45)$ \\
Appointment duration, mins, median (range) & \\
Client testing & $67(48.2)$ \\
Clients tested, no. (\%) & $67(100)$ \\
\hline Negative tests, no. $(\%)^{\S}$ &
\end{tabular}

Abbreviation: COVID-19 = coronavirus disease 2019.

* All interviews were conducted via telephone by the Greene County Health Department.

${ }^{\dagger}$ After onset of symptoms in stylist A.

$\S$ Among those tested.

between clients and stylists. These results support the use of face coverings in places open to the public, especially when social distancing is not possible, to reduce spread of SARS-CoV-2.

Although SARS-CoV-2 is spread largely through respiratory droplets when an ill person coughs or sneezes (1), data suggest that viral shedding starts during the 2-to-3-day period before symptom onset, when viral loads are at their highest (2). Although the rate of transmission of SARS-CoV-2 from presymptomatic patients (those who have not yet developed symptoms) and asymptomatic persons (those who do not develop symptoms) is unclear, these persons likely contribute to the spread of SARS-CoV-2 (3). With the potential for presymptomatic and asymptomatic transmission, widespread adoption of policies requiring face coverings in public settings should be considered to reduce the impact and magnitude of additional waves of COVID-19.

Previous studies show that both surgical masks and homemade cloth face coverings can reduce the aerosolization of virus into the air and onto surfaces $(4,5)$. Although no studies have examined SARS-CoV-2 transmission directly, data from previous epidemics $(6,7)$ support the use of universal face coverings as a policy to reduce the spread of SARS-CoV-2, as does observational data for COVID-19 in an analysis of 194 countries that found a negative association between duration of a face mask or respirator policy and per-capita coronavirus-related mortality; in countries that did not recommend face masks and respirators, the per-capita coronavirus-related mortality increased each week by $54.3 \%$ after the index case, compared with $8.0 \%$ in those countries with masking policies (CT Leffler, Virginia Commonwealth University, unpublished data, 2020). ${ }^{\S}$ Similar outcomes have been observed for other respiratory virus outbreaks, including the 2002-04 outbreak of Severe Acute Respiratory Syndrome

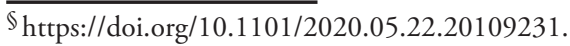


TABLE 2. Hair salon clients' $(N=104)$ responses to interview questions* about their interactions with two stylists with COVID-19 during salon appointments - Springfield, Missouri, May 12-20, 2020

\begin{tabular}{|c|c|c|}
\hline Interview question & Response & No. (\%) \\
\hline $\begin{array}{l}\text { Did you wear a face } \\
\text { covering? }\end{array}$ & $\begin{array}{l}\text { Yes, for the entire appointment } \\
\text { Yes, for part of the appointment } \\
\text { No, not at all } \\
\text { Did not know }\end{array}$ & $\begin{array}{r}102(98.1) \\
2(1.9) \\
0(-) \\
0(-)\end{array}$ \\
\hline $\begin{array}{l}\text { What type of } \\
\text { face covering did } \\
\text { you wear? }\end{array}$ & $\begin{array}{l}\text { Cloth face covering } \\
\text { Surgical mask } \\
\text { N95 respirator }{ }^{\dagger} \\
\text { Did not know } \\
\text { Did not answer question }\end{array}$ & $\begin{array}{r}49(47.1) \\
48(46.1) \\
5(4.8) \\
2(1.9) \\
0(-)\end{array}$ \\
\hline $\begin{array}{l}\text { Did the stylist wear } \\
\text { a face covering? }\end{array}$ & $\begin{array}{l}\text { Yes, for the entire appointment } \\
\text { Yes, for part of the appointment } \\
\text { No, not at all } \\
\text { Did not know }\end{array}$ & $\begin{array}{r}101(97.1) \\
0(-) \\
0(-) \\
3(2.9)\end{array}$ \\
\hline $\begin{array}{l}\text { What type of } \\
\text { face covering did } \\
\text { the stylist wear? }\end{array}$ & $\begin{array}{l}\text { Cloth face covering } \\
\text { Surgical mask } \\
\text { N95 respirator } \\
\text { Did not know } \\
\text { Did not answer question }\end{array}$ & $\begin{array}{r}39(37.5) \\
25(24.0) \\
0(-) \\
35(33.7) \\
5(4.8)\end{array}$ \\
\hline $\begin{array}{l}\text { Did you have a } \\
\text { respiratory illness in } \\
\text { the past } 90 \text { days? }\end{array}$ & $\begin{array}{l}\text { Yes } \\
\text { No } \\
\text { Did not know } \\
\text { Did not answer the question }\end{array}$ & $\begin{array}{r}7(6.7) \\
87(83.7) \\
1(1.0) \\
9(8.7)\end{array}$ \\
\hline
\end{tabular}

Abbreviation: COVID-19 = coronavirus disease 2019.

* All interviews were conducted via telephone by the Greene County Health Department.

+ Particulate-filtering facepiece respirators that filter $\geq 95 \%$ of airborne particles (https://www.cdc.gov/niosh/npptl/topics/respirators/disp_part/n95list1. html).

(SARS) (G) and the 2007-08 influenza season (7). A systematic review on the efficacy of face coverings against respiratory viruses analyzed 19 randomized trials and concluded that use of face masks and respirators appeared to be protective in both health care and community settings (8).

The findings in this report are subject to at least four limitations. First, whereas the health department monitored all exposed clients for signs and symptoms of COVID-19, and no clients developed symptoms, only a subset was tested; thus, asymptomatic clients could have been missed. Similarly, with a viral incubation period of 2-14 days, any COVID-19 PCR tests obtained from clients too early in their course of infection could return false-negative results. To help mitigate this possibility, all exposed clients were offered testing on day 5 and were contacted daily to monitor for symptoms until day 14 . Second, although the health department obtained supplementary data, no information was collected regarding underlying medical conditions or use of other personal protective measures, such as gloves and hand hygiene, which could have influenced risk for infection. Third, viral shedding is at its highest during the 2 to 3 days before symptom onset; any clients who interacted with the stylists before they became symptomatic were not recruited for contact tracing. Finally, the mode of interaction between stylist and client might have limited the potential for exposure to the virus. Services at salon A were limited to haircuts, facial hair trimmings, and perms. Most stylists cut hair while clients are facing away from them, which might have also limited transmission.

The results of this study can be used to inform public health policy during the COVID-19 pandemic. A policy mandating the use of face coverings was likely a contributing factor in preventing transmission of SARS-CoV-2 during the close-contact interactions between stylists and clients in salon A. Consistent and correct use of face coverings, when appropriate, is an important tool for minimizing spread of SARS-CoV-2 from presymptomatic, asymptomatic, and symptomatic persons. CDC recommends workplace policies regarding use of face coverings for employees and clients in addition to daily monitoring of signs and symptoms of employees, procedures for screening employees who arrive with or develop symptoms at work, and posted messages to inform and educate employees and clients (https://www.cdc.gov/coronavirus/2019ncov/community/organizations/businesses-employers.html).

\section{Acknowledgments}

Alina Ainyette, Megan Rippee-Brooks, Jodi Caruthers.

Corresponding author: Robin Trotman, robintrotman@sbcglobal.net.

${ }^{1}$ Washington University School of Medicine, St. Louis, Missouri; ${ }^{2}$ University of Kansas Medical Center, Kansas City, Missouri; ${ }^{3}$ Springfield-Greene County Health Department, Springfield, Missouri; ${ }^{4}$ CoxHealth Infection Prevention Services, Springfield, Missouri.

All authors have completed and submitted the International Committee of Medical Journal Editors form for disclosure of potential conflicts of interest. Robin Trotman reports personal fees from Merck outside the published work. No other potential conflicts of interest were disclosed.

\section{References}

1. CDC. Clinical questions about COVID-19: questions and answers. Atlanta, GA: US Department of Health and Human Services, CDC; 2020. https://www.cdc.gov/coronavirus/2019-ncov/hcp/faq.html

2. He X, Lau EHY, Wu P, et al. Temporal dynamics in viral shedding and transmissibility of COVID-19. Nat Med 2020;26:672-5. https://doi. org/10.1038/s41591-020-0869-5

3. Oran DP, Topol EJ. Prevalence of asymptomatic SARS-CoV-2 infection: a narrative review. Ann Intern Med 2020;M20-3012. https://doi. org/10.7326/M20-3012

4. Konda A, Prakash A, Moss GA, Schmoldt M, Grant GD, Guha S. Aerosol filtration efficiency of common fabrics used in respiratory cloth masks. ACS Nano 2020;14:6339-47. https://doi.org/10.1021/acsnano.0c03252

5. MacIntyre CR, Seale H, Dung TC, et al. A cluster randomised trial of cloth masks compared with medical masks in healthcare workers. BMJ Open 2015;5:e006577. https://doi.org/10.1136/bmjopen-2014-006577

6. Lau JT, Tsui H, Lau M, Yang X. SARS transmission, risk factors, and prevention in Hong Kong. Emerg Infect Dis 2004;10:587-92. https:// doi.org/10.3201/eid1004.030628

7. Aiello AE, Perez V, Coulborn RM, Davis BM, Uddin M, Monto AS. Facemasks, hand hygiene, and influenza among young adults: a randomized intervention trial. PLoS One 2012;7:e29744. https://doi. org/10.1371/journal.pone.0029744

8. MacIntyre CR, Chughtai AA. A rapid systematic review of the efficacy of face masks and respirators against coronaviruses and other respiratory transmissible viruses for the community, healthcare workers and sick patients. Int J Nurs Stud 2020;108:103629. https://doi.org/10.1016/j. ijnurstu.2020.103629 